\title{
O AMOR ENTRE FILOSOFIA E PSICANÁLISE
}

Claudia Murta

\begin{abstract}
Resumo
Investigamos a condição do amor como ponto de inflexão entre a filosofia e a psicanálise. A referência escolhida no campo de possibilidades de relação entre a filosofia e a psicanálise baseia-se no pensamento de Lacan. A possibilidade de relação entre dois discursos distintos é abordada, no pensamento lacaniano, a partir de seu aforismo maior, segundo o qual "não há relação sexual". Mesmo para a relação que não existe, Lacan propõe uma suplência - o amor, o qual surge como uma das suplências possíveis para a "relação sexual impossivel" que pode se apresentar como um campo possível para a relação entre a filosofia e a psicanálise.
\end{abstract}

Palavras-chave: Amor. Homem. Mulher. Filosofia. Psicanálise.

\section{LOVE BETWEEN PHILOSOPHY AND PSYCHOANALYSIS}

\begin{abstract}
We investigate the condition of love as a point of inflection between philosophy and psychoanalysis. Taken in the field of possibilities of relation between philosophy and psychoanalysis, this reference is based on Lacan's thought. The possibility of relation between two distinct ways of thinking is focused on Lacan's thought from his main aphorism "there is not sexual relation". Lacan proposes a supplementing for this relation that does not exist - love. So love appears as one possible supplementing for an "impossible sexual relation" and as a possible field of relation between philosophy and psychoanalysis.
\end{abstract}

Keywords: Love. Man. Woman. Philosophy. Psychoanalysis.

^ Professora doutora do Departamento de Filosofia da UFES.

Endereço: Rua Amélia Tartuce Nasser, 91/302, Jardim da Penha, CEP: 29065-020.

E-mail: cmurta@terra.com.br 


\section{O AMOR COMO SUPLÊNCIA}

O termo suplência foi apontado, em sua relação com o amor, por Lacan (1975) em O Seminário - Encore. Nesse Seminário de Lacan, encontramos a seguinte frase: "aquilo que dá suplência à relação sexual é precisamente o amor" (LACAN, 1975, p. 44). O termo "amor" é trabalhado nesse contexto como suplência, dando a essa suplência a perspectiva da transmissão entre os dois lados disjuntos da sexuação. O amor que, a partir do pensamento de Lacan, permite a transmissão de algo entre as duas realidades distintas do sexo, surge do lado feminino e se direciona para o lado masculino. Desse modo, podemos partir do princípio de que a origem do amor é feminina.

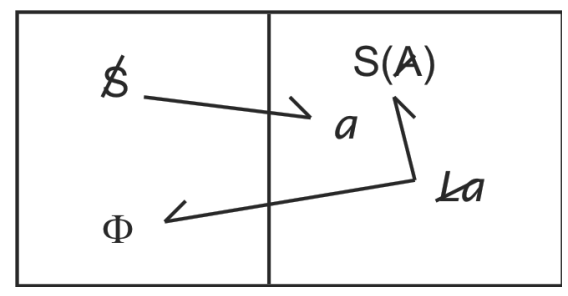

\section{“A Relação Sexual Não Existe"}

No quadro apresentado (LACAN, 1975, p. 73) situa as possíveis relações entre os dois lados, chamados por Lacan "lado homem" e "lado mulher" da posição do ser sexuado. Devemos lembrar que a divisão entre parte "homem" e parte "mulher" da sexuação não implica a anatomia que porta o ser falante. Além do mais, devemos frisar que a proposição de relação entre os dois lados é problemática, pois o quadro da sexuação é justamente construído para provar que "não existe relação sexual". Se "não existe relação sexual", como é possível falar de relação entre os dois lados da sexuação? Se não é questão de relação nesse contexto, como podemos nomear o "traspassamento" de flechas disposto nesse quadro?

Os termos apresentados nesse quadro são, respectivamente: do lado homem $\mathcal{S}^{\mathrm{e}} \boldsymbol{\Phi}$, e do lado mulher $S(A) a$ e $\bigvee_{\mathrm{a}}$ Antes mesmo de comentar a implicação desses elementos nessa elaboração, devemos seguir sua apresentação, tal como Lacan a desenvolve. Primeiramente, temos a apresentação dos elementos do lado masculino:

Do lado do homem, inscrevi aqui, não certamente para privilegiá-lo de modo algum, $\boldsymbol{S}$ e o $\boldsymbol{\Phi}$ que o suporta como significante, o que se encarna também no $S_{1}$, que é, entre todos os significantes, esse significante para o qual não há significado, e que, quanto ao sentido, simboliza o fracasso (LACAN, 1975, p. 74). 
A partir desse esclarecimento, podemos apreender que o termo principal que delimita o lado masculino é o $\boldsymbol{\Phi}$, o Phallus, pois é ele que suporta o $\boldsymbol{S}$, o sujeito do inconsciente. $\mathrm{O} \Phi$ é o significante ímpar; ele é o único que existe, já que, tanto para o homem quanto para a mulher, a sexuação passa pela função fálica.

Lacan explicita que a existência solitária do Phallus simboliza o fracasso. O fracasso é um outro nome para a castração e testemunha que um sexo não entra em relação com o Outro do sexo oposto, não havendo, assim, relação sexual. Isso nos faz retornar à questão antecedente: se "não há relação sexual", por que existem flechas entre os dois lados? Essa problemática é esclarecida quando Lacan enuncia que:

esse $\boldsymbol{S}$ só tem a ver, enquanto parceiro, com o objeto $\boldsymbol{a}$ inscrito do outro lado da barra. Só lhe é dado atingir seu parceiro sexual, que é o Outro, por intermédio disto, de ele ser a causa de seu desejo. A este título, como o indica alhures em meus gráficos, a conjunção apontada desse $\boldsymbol{S e}$ desse $\boldsymbol{a}$, isto não é outra coisa senão fantasia (LACAN, 1975, p. 75).

Assim, podemos apreender que fantasia é o nome da única flecha que religa os dois lados tendo como origem o lado masculino. Ao observar o sentido das flechas apresentadas no quadro em questão, podemos considerar que a fantasia é a única forma de acesso ao lado feminino partindo pela via do lado masculino. Que a fantasia permita o acesso ao lado mulher não implica que $\delta$, o sujeito, possa ter acesso ao Outro do outro lado; pois do Outro, ele se relaciona apenas ao que se extrai, o objeto $\boldsymbol{a}$. Visto que não há relação entre os dois lados, o objeto $\boldsymbol{a}$ vai suplementar a ausência de relação sexual. Segundo Lacan: "do lado do homem, é que aquilo com o que ele tem a ver, é com o objeto $\boldsymbol{a}$, e que toda a sua realização quanto à relação sexual termina na fantasia" (LACAN, 1975, p. 80). Desse modo, Lacan pode dizer que a relação sexual só se realiza na fantasia.

Elucidando a primeira flecha do quadro, tivemos a oportunidade de abordar um dos elementos localizados no lado mulher, o objeto $\boldsymbol{a}$. Contudo, ele não é o único; dois outros elementos estão também presentes: o $\swarrow$ a e o $S(A)$. O $\swarrow$ a resume a frase "A mulher não existe" e, segundo Lacan, "esse La é um significante para o qual é próprio ser o único que não significa nada" (LACAN, 1975, p. 68). Se comparamos essa definição do $\swarrow$ a à definição do $\Phi$ que é o significante para o qual não tem significado, nós temos condições de apreender um pouco melhor os limites entre o lado homem e o lado mulher, visto que, do lado homem é questão do significante ímpar, o único que existe, enquanto do lado mulher é questão do significante que não é nada, não podendo nem mesmo ter uma existência mínima.

Desse $\swarrow$ a, que não existe, originam-se, contudo, duas flechas: uma que alcança o $\boldsymbol{\Phi}$ do outro lado, do lado homem, e outra que alcança o $S(A)$ do mesmo lado. Lacan comenta esse desdobramento da seguinte forma: "a mulher tem relação com $S(A)$, e já é nisso que ela se duplica, que ela não é toda, pois, por outro lado, ela pode ter relação com $\Phi$ "' (LACAN, 1975, p. 75). O desdobramento des- 
sas duas flechas implica o "não-todo". Esse "não-todo" não implica algo a menos, ao contrário ele implica algo a mais, pois é o "não-todo" que condiciona o desdobramento do $\mathscr{L}$ a em sua relação. Essa relação é o que Lacan nomeia gozo.

É importante sublinhar que a disposição das flechas no quadro em questão determina que: tendo como origem o lado homem, a única relação possível entre os dois lados é a fantasia; enquanto, do outro lado, tendo como origem o lado mulher, é o gozo que, em uma de suas vertentes, coloca-os em relação. Assim, a partir da disposição dessas flechas, podemos perguntar se o gozo origina-se sempre do lado mulher e a fantasia, por sua vez, origina-se sempre do lado homem. Além do mais, visto que para Lacan "não existe relação sexual", a fantasia e o gozo apresentam-se como dois meios disponíveis para que esses dois lados tenham um semblante de relação.

Como nós já evocamos a fantasia quando abordamos o lado homem, devemos agora concentrar nossos esforços sobre o conceito lacaniano de gozo. O gozo surge do $\measuredangle$ a e, em parte, é relacionado ao $\boldsymbol{\Phi}$ do lado homem, sendo nomeado como gozo fálico; de outro modo, o gozo se mantém exclusivamente do lado mulher onde é relacionado ao $S(\mathbb{A})$, sendo designado como gozo feminino. Devemos sublinhar que o gozo fálico é, entre os dois gozos, o único que coloca em relação os dois lados. Como essa relação não é a relação sexual, Lacan propõe uma equivalência entre o gozo fálico e a inexistência da relação sexual.

Segundo Lacan, esse gozo exprime a impossibilidade da relação sexual porque ele não é o gozo do corpo, ele é aquele que o suplementa, o gozo fálico: "o gozo, enquanto sexual, é fálico, quer dizer, ele não se relaciona com o Outro como tal" (LACAN, 1975, p. 14). Dessa forma, gozo sexual é um outro nome para designar o gozo fálico, mas como pode haver um gozo dito sexual sem relação sexual? A observação segundo a qual esse gozo não se relaciona com o Outro é um início de resposta. Já que ele não se relaciona com o Outro, o gozo fálico mantém a inexistência dessa relação, pois não é pelo seu intermédio que um sexo vai se relacionar com o Outro do sexo oposto.

Uma das designações de Lacan para gozo fálico é: o gozo "que não deveria" (LACAN, 1975, p. 55). A fim de assimilar uma tal designação, deve-se tomar a questão a partir da inexistência da relação sexual. A inexistência da relação sexual gera um gozo que não deveria se, justamente, nós quiséssemos ter o gozo da relação sexual. Esse gozo "que não deveria" é um gozo que, pelo fato mesmo de que ele existe, manifesta que o gozo que nós podemos esperar da relação sexual é um gozo perdido. De outro modo, o gozo "que não deveria", esse que nós temos a nossa disposição, opõe-se ao gozo que deveria se nós quiséssemos gozar da relação sexual. Esse gozo que deveria é, ao mesmo tempo, aquele que nós esperamos, visto que habitamos a linguagem, e esse que nos é impedido de conseguir, já que falamos. Como o gozo "que não deveria" é também o gozo sexual, seu princípio é, nessas condições, a perda. Assim, ele perde o gozo da relação sexual e, como a fantasia, essa perda é um outro modo de realizar a relação entre os dois lados. Segundo Lacan: 
Por causa do que ele fala, o tal gozo, ela, a relação sexual, não existe. É mesmo por isso que ele faz melhor em se calar, com o resultado de que isto torna a ausência mesma da relação sexual um pouco mais pesada ainda. E é mesmo por isso que, no fim das contas, ele não se cala, e que o primeiro efeito do recalque é que ele fala de outra coisa. É nisto que está a mola da metáfora (LACAN, 1975, p. 57).

Isso nos permite descobrir que o gozo fálico, equivalente ao gozo "que não deveria" é igualmente equivalente ao gozo sexual que é, ele próprio, equivalente ao gozo da palavra, um gozo, como o nomeia Lacan, do blá-blá. Ele pode ser chamado gozo do blá-blá, visto que, para Lacan, o ser humano é antes de tudo um ser falante. Podemos abordar a questão do seguinte modo: o gozo fálico é o gozo da palavra, visto que ela é um obstáculo ao gozo do corpo. Devemos lembrar que o gozo fálico se origina do lado mulher, do $\swarrow$ a que não significa nada, pois seu objetivo se encontra do outro lado, no significante fálico; é a partir desse encontro com o significante que o gozo pode ser dito e ter sua parte de existência. Segundo Lacan: "o significante é a causa do gozo. Sem o significante, como mesmo abordar essa parte do corpo? Como, sem o significante, centrar esse algo que, do gozo, é a causa material? [...] o significante é aquilo que pára o gozo" (LACAN, 1975, p. 27).

Como nos explicita Lacan, o significante é causa do gozo, pois é apenas a partir do seu encontro que o gozo pode ter uma certa existência. Se não existisse o significante, não seria possível falar de gozo. Se de um lado ele é sua causa, do outro ele o interrompe, visto que, por sua origem, o gozo é interditado ao ser falante sujeito à castração. É nesse sentido que Lacan anuncia "se houvesse outro, mas não há outro gozo senão o fálico" (LACAN, 1975, p. 56). Essa observação é muito importante, visto que ela coloca em questão o desdobramento dos gozos. Ora, se o gozo fálico é o único que existe, por que Lacan mencionou um outro gozo?

Se o gozo fálico é o único que existe, por que existe do lado mulher uma flecha que se origina no $\swarrow$ a e termina no $S(A)$ ? Como resposta, nós podemos acrescentar que o gozo fálico toma sua parte de existência apenas no momento em que a flecha alcança o $\boldsymbol{\Phi}$ ? que é o único que existe. Como do lado mulher não é possível falar de existência, mínima que seja, o gozo que está aí presente também não pode existir. Assim, tanto quanto o $\mathcal{L}$ a o s(A)e mesmo o objeto $\boldsymbol{a}$, o gozo que se aloja do lado mulher não existe. Uma tal disposição nos leva a perguntar o motivo pelo qual Lacan (LACAN, 1975, p.69) tem necessidade de se referir ao gozo feminino, já que ele sabe, desde o início, que não existe. Para esclarecer essa questão vamos ver os termos com os quais ele trata esse gozo:

Há um gozo dela, desse ela que não existe e não significa nada. Há um gozo dela sobre o qual talvez ela mesma não saiba nada a não ser que o experimenta - isto ela sabe. Ela sabe disso, certamente, quando isso acontece. Isso não acontece a elas todas (LACAN, 1975, p. 69). 
Como podemos entender o início dessa citação, já que assimilamos que só existe um gozo, o gozo fálico? Lacan anuncia que esse gozo, que nós não conseguimos saber nem se existe nem se não existe, não é, justamente, da ordem do saber. Para podermos nos dar conta da sua presença devemos vivê-lo.

Trata-se de uma reviravolta em cima da aposta de algo que se vive sem que possamos saber o que é. Por meio desse gozo, Lacan nos apresenta algo que nós não podemos saber nem se existe, nem se não existe e que, no entanto, se vive. Lembramos, mais uma vez, que o pouco de ser que Lacan admite do lado homem se traduz no fato de que algo possa ser dito. Esse gozo feminino é um gozo do qual nada pode ser dito que o torne formulável.

O gozo feminino existe, sem existir e como não tem nenhuma relação com a parte de existência presente no lado homem, não podemos nada dizer sobre ele. Como não seria simples deixar as coisas nesse estado, mencionando um gozo que existe e ao mesmo tempo não existe, Lacan nos oferece alguns exemplos:

[...] é como para Santa Tereza - basta olhar em Roma a estátua de Bernini para compreenderem logo que ela está gozando, não há dúvida. E do que é que ela goza? É claro que o testemunho essencial dos místicos é justamente o de dizer que eles o vivem, mas não sabem nada dele (LACAN, 1975, p. 71).

Assim, a mística é um dos exemplos privilegiados por Lacan para designar o gozo feminino, além do mais a estátua de Santa Teresa à qual ele faz alusão torna-se a capa de $O$ Seminário - Encore. Para Lacan, o gozo místico é da ordem desse gozo que não é o gozo fálico. Com o exemplo das místicas, Lacan consegue dar uma certa idéia do que se trata no que diz respeito a esse gozo feminino.

Além dos místicos, Lacan oferece a si mesmo como um outro exemplo desse gozo que se vive. O fato de Lacan ter-se incluído nesses exemplos de gozo é muito importante, pois como ele poderia afirmar a existência de um gozo que é somente vivido se, ele mesmo, não o tivesse vivido? Nesse sentido, além da literatura dos místicos, ele indica a seus auditores "Acrescentar os Escritos de Jacques Lacan, porque é da mesma ordem” (LACAN, 1975, p. 71).

E no texto de L'étourdit, Lacan precisa: "é a conquista da análise ter feito matema, quando a mística anteriormente testemunhava sua prova apenas fazendo o indizível" (LACAN, 1973, p. 42). Esse enunciado confirma que sua posição se distingue da posição mística, independentemente do fato de que tanto Lacan quanto os místicos testemunham a prova de um gozo feminino. Os matemas lacanianos permitem que esse gozo, que se mostra de uma outra ordem, torne-se abordável; é por isso que os matemas têm a função essencial de permitir a transmissão.

O matema é, para Lacan, aquilo que se localiza entre a palavra e a escrita. Como Lacan não nos coloca na perspectiva de imposição do dizer sobre o indizível, ele articula à palavra a escrita. A função do matema é transmitir algo da ordem do saber sem a utilização exclusiva da palavra. O matema proporciona a transmissão de saber entre duas realidades distintas - homem e mulher. Ao escapar ao uso 
exclusivo da palavra, o matema pode transitar entre os dois lados disjuntos da sexuação, visto que a palavra, por ser de ordem fálica, é eminentemente masculina. O uso exclusivo da palavra implica a fixação do lado homem e a inacessibilidade do lado mulher da sexuação por ser esse o lado do silêncio. O matema oferece uma alternativa para que a impossibilidade da relação entre os sexos não os deixe imóveis, fixados em suas posições respectivas. Como enuncia Milner: "a possibilidade e a necessidade do matema vem disso que o ser falante é sexuado" (MILNER, 1995, p. 131).

O matema desfaz o paradoxo. O próprio Lacan anuncia que "aquilo que dá suplência à relação sexual é precisamente o amor" (LACAN, 1975, p. 44). Assim, em sua elaboração, o matema é o conceito que denota a presença desse movimento amoroso. Ele é a condição da instauração desse amor. O matema faz passar o ponto onde pode haver amor. A partir daí, podemos dizer que esse amor é a transmissão, isto é, a função principal do matema. Como o matema mantém sua função principal de transmissão via suplência do amor, ele também permite a suplência da relação entre a filosofia e a psicanálise, já que faz a confluência para o tema fundamental da Filosofia e da Psicanálise - o amor.

\section{O AMOR DE DIOTIMA}

Um exemplo dessa questão da transmissão é oferecido por Lacan, ao apresentar a posição de Sócrates, em O Banquete de Platão (apud LACAN, 1991). Sócrates, no momento de fazer seu discurso, evoca a palavra de Diotima. Essa ação por parte de Sócrates foi muito questionada pelos seus comentadores. Segundo Lacan (1991), ao comentar O Banquete em O Seminário - A Transferência, Sócrates delega a Diotima o saber sobre o amor pelo fato de seu método não ser apropriado para aventar sobre o amor. Para Lacan, a dialética jamais poderia controverter verdadeiramente o amor, pois o seu regime de trabalho impõe o discurso masculino.

Quando a palavra de Diotima é anunciada, facilmente, pode-se perceber que seu discurso não é da ordem da dialética e, sim, da ordem do mito. Ela conta que o amor nasceu da união entre Poros e Pênia. Fruto da conexão entre dois extremos opostos $-\mathrm{o}$ recurso e a miséria. $\mathrm{O}$ amor vem a ser apresentado, no discurso de Diotima, como "dar o que não se tem". Dar o que não se tem, em decorrência de sua origem pobre e cheia de recurso.

Mesmo estando entre dois opostos e, sempre sendo delimitado a partir dessa posição intermediária, o amor nasce porque a pobreza toma a posição ativa de seduzir o recurso. Tendo em vista que amar é antes de tudo um verbo, implicando assim uma ação, a parte ativa do amor tem uma importância muito relevante no seu processo de delimitação. Poros, no mito, está em posição passiva e, dessa forma, estabelece a direção da atividade do amor. Mesmo que Poros dê uma direção a esse amor, a ação do amor se origina em Pênia e, assim sendo, é feminina a origem do amor. Para Lacan, isso explica o fato de Sócrates ter passado a uma mulher a palavra sobre o amor: "por uma singular divisão, é a mulher, a mulher 
que está nele, eu já disse, talvez, que a partir de um certo momento, Sócrates deixa falar" (LACAN, 1991, p. 151).

Estando a origem do amor no feminino, seu destino é o masculino. Sócrates não poderia falar de amor partindo exclusivamente da posição masculina. Ele precisa partir de uma posição feminina, nomeada por ele como Diotima, para referenciá-la em sua posição masculina enquanto Sócrates mesmo. Desse modo, podemos perceber que o amor se origina no feminino e só se transforma em palavras a partir de sua finalização no masculino.

\section{AMOR DE CORPO E ALMA}

Para a origem feminina do amor, a referência a $O$ Banquete de Platão foi apropriada. Contudo, seguindo o pensamento de Platão sobre o amor, não conseguimos nos aproximar de sua referência corporal. Tal referência oferece subsídios para que se possa situar o amor como elemento de transmissão entre duas realidades distintas. Assim, para a inclusão da noção de corpo no tema do amor, a referência ao texto de Descartes (1979a), As paixões da alma, torna-se mais adequada. A questão central dessa parte de nosso texto visa ao encontro da maneira pela qual o amor, enquanto paixão, pode convulsionar o corpo. Quando Descartes apresenta As paixões da alma, ele indica o seguinte caminho de investigação: "que não existe melhor caminho para chegar ao conhecimento de nossas paixões do que examinar a diferença que há entre a alma e o corpo, a fim de saber a qual dos dois se deve atribuir cada uma das funções existentes em nós" (DESCARTES, 1979a, p. 217).

Sendo, para Descartes, o amor uma das paixões primitivas, ele o classifica como sendo uma das paixões que dependem do corpo. No texto de Descartes, em nota, encontramos a seguinte afirmação: "enquanto paixão, o amor não é apenas a antecipação consciente do bem ao qual desejo estar unido: esta antecipação tornase inseparável de sua ressonância orgânica" (DESCARTES, 1979a, p. 248). Essa ressonância orgânica permite que possamos acompanhar as consequiências da paixão no corpo humano. A ressonância orgânica pode indicar a presença do amor onde inicialmente ele não se faz perceber. Isso é muito importante, pois o corpo pode ser o índice da paixão que afeta a alma. Se conseguimos chegar à paixão, conseguimos chegar ao pensamento, já que o amor, sendo uma paixão da alma, é um pensamento, por mais confuso que se apresente. A confusão pela qual esse pensamento se apresenta decorre, para Descartes, de sua manifestação a partir de uma estreita aliança entre corpo e alma.

Podemos perceber que, a partir do texto de As paixões da alma, Descartes discorre sobre as paixões para que as almas mais fracas possam domá-las e conduzi-las. No seu entender, uma alma que se deixa arrastar pelas paixões é uma alma escrava e infeliz. Tendo em vista a aliança de corpo e alma presente nas paixões e, uma vez que a alma é de natureza distinta do corpo, o objetivo de se livrar completamente das paixões é impensável. A alma não tem acesso direto ao corpo, nem pode excitar diretamente as paixões. Pois, a paixão é algo que se apropria do corpo 
e, segundo Descartes, "o principal efeito de todas as paixões nos homens é que incitam e dispõem a sua alma a querer coisas para as quais elas lhes preparam os corpos" (DESCARTES, 1979a, p. 232). Assim, por mais que as paixões sejam da alma, elas estão intimamente ligadas ao corpo e, por esse mesmo motivo, o controle das paixões não é da ordem da vontade. Podemos perceber, a partir do texto cartesiano, que a necessidade de dominar as paixões se apresenta devido ao fato de elas tenderem à patologia. Dentro dessa perspectiva, citamos um comentário de François Regnault, filósofo, comentador de textos psicanalíticos, que nos apresenta a paixão do amor como uma doença. Para ele, "Em que o nome de doença é pertinente? Diremos que é para toda teoria a qual mantém que, no amor, alguma coisa da alma suporta alguma coisa do corpo, ou inversamente" (REGNAULT, 1999, p. 67). A ressonância orgânica das paixões pode levá-las a serem qualificadas, se seguirmos o comentário de François Regnault, como doença. Essa é uma leitura do amor apropriada para uma aproximação possível com o campo da psicanálise. A percepção do amor como uma patologia qualifica a psicanálise para o tratamento do amor.

O modo pelo qual o amor afeta o corpo apresenta alguns efeitos. Para que se possa perceber, a partir da psicanálise, de que forma o amor afeta o corpo, uma citação do texto de Jacques-Alain Miller, "A biologia lacaniana", torna-se apropriada: "[...] afetar um corpo. [...] O efeito de 'afetar' inclui, também, o efeito do sintoma, o efeito do gozo, e mesmo o efeito do sujeito, mas efeito do sujeito situado num corpo e não efeito de pura lógica" (MILLER, 2004, p. 52). A partir dos esclarecimentos de Miller, podemos perceber que a tentativa de efetuar uma lógica da sexuação se mantém distanciada do ato de afetar o corpo. $\mathrm{O}$ amor, ao afetar o corpo, pode produzir alguns efeitos de sintoma, gozo ou mesmo sujeito. Cabe ao campo que é próprio da psicanálise abordar o campo do sintoma, do gozo e mesmo do sujeito como manifestações da paixão do amor, pois tais manifestações permitem a percepção da inscrição da paixão do amor no corpo.

\section{TER UM CORPO}

Na sessão do dia 11 de maio de 1976 do Seminário 23 - O Sinthoma, Lacan enuncia:

Ter relação a seu próprio corpo como estrangeiro é, de fato, uma possibilidade. É bem aquilo que exprime o uso do verbo ter - o corpo, pode-se ter, não sê-lo em nenhum grau, e é o que faz crer na alma, à guisa de que se pensa ter uma alma, $\mathrm{o}$ que é o cúmulo (LACAN, 1976-77, p. 7).

Essa declaração de Lacan traduz-se como bastante apropriada dentro do âmbito do entendimento sobre a distinção de corpo e alma apresentada por Descartes.

No texto de suas Meditações Metafísicas, na meditação sexta, Descartes se propõe a examinar "a existência das coisas materiais e da distinção real entre a alma e o corpo do homem". Em suas palavras: 
[...] embora talvez (ou, antes, certamente, como direi logo mais) eu tenha um corpo ao qual estou muito estreitamente conjugado, todavia, já que, de um lado, tenho uma idéia clara e distinta de mim mesmo, na medida em que sou apenas uma coisa pensante e inextensa, e que, de outro, tenho uma idéia distinta do corpo, na medida em que é apenas uma coisa extensa e que não pensa, é certo que este eu, isto é, minha alma, pela qual eu sou o que sou, é inteira e verdadeiramente distinta de meu corpo e que ela pode ser ou existir sem ele (DESCARTES, 1979b, p. 134).

A citação do texto de Descartes esclarece que a distinção entre corpo e alma faz-se necessária, já que o sujeito pensante, a alma, o eu que participa do ser, não se define por sua conjugação com o corpo, mas sim, exclusivamente, por sua participação de algo da ordem do ser. Essa participação do sujeito no ser é o que garante a ontologia cartesiana. A relação, proposta por Descartes, do sujeito com o ser é fundamental em seu pensamento. No texto A ciência e a verdade, Lacan comenta que Descartes "pretende fundar para o sujeito um certo ancoramento no ser" (LACAN, 1966, p. 856). O fato de o sujeito proposto por Descartes estar ancorado no ser é primordial para percebermos a distinção entre o corpo e a alma em sua teoria. Pois, de acordo com o texto de Descartes, o eu permite a condição de ser. Assim, pode-se perceber que a alma garante a condição de ser e essa condição não tem relação com o corpo. No Discurso do Método, Descartes esclarece que a alma "não pode ser de modo algum tirada do poder da matéria" (DESCARTES, 1979c, p. 61). O corpo não tem alma, não se pode ter uma alma, tendo em vista que à alma só é legada a condição de ser - é o que vem corroborar a distinção entre corpo e alma. Diferentemente dos escolásticos, Descartes não aceita a idéia de alma sensitiva ou vegetativa pertencente ao corpo. A presença da alma no corpo poderia assegurar ao corpo a condição de ser. De forma alguma, no pensamento cartesiano, o corpo poderia, independentemente da alma, participar da condição de ser. É isso que afirma Lacan na citação de $O$ Seminário: 23. Sobre esse ponto, em Elementos de uma biologia lacaniana, Jacques-Alain Miller comenta que:

Muitas vezes fiquei impressionado por Lacan fazer questão de que se dissesse que o homem "tem" um corpo, e não que ele "é” um corpo. Acredito ter entendido o porquê. É porque, para o homem, não se pode fazer equivaler ser e corpo, enquanto para o animal isso é possível. O sujeito não pode se identificar com o seu corpo, e é daí, precisamente, que vem a turgidez narcísica que atrapalha as suas relações com o mundo. Não podemos evitar o paradoxo do corpo vivo e falante (MILLER, 1997, p. 73).

O comentário de Miller esclarece que a insistência de Lacan para que se mantenha a idéia do uso do verbo ter vinculado à noção de corpo diz da impossibilidade de o homem poder ser um corpo. A disposição de Lacan segue, então, a proposição de Descartes que, comentada por Alexandre Koyré, toma o seguinte formato: "eu tenho um corpo, mas eu não sou um corpo" (KOYRÉ, 1962, p. 227). 
Tal formulação é bastante elucidativa quanto à determinação de Descartes em não permitir uma relação direta entre algo que é da ordem do ser e o corpo. Para Koyré, essa distinção trata de uma descoberta genial de Descartes. A insistência de Lacan quanto ao fato de se ter e não ser um corpo aponta para a sua filiação cartesiana quanto à relação do sujeito com o corpo. Ainda na sessão de 11 de maio de 1976 de seu Seminário, Lacan acrescenta que "o homem diz do corpo que ele é seu. Ele acredita que o possui, como um móvel, o que não permite de modo algum definir um sujeito" (LACAN, 1976-77, p. 9). Essa afirmação confirma que o fato de se ter um corpo não garante a ordem do ser para o sujeito. No entanto, além de tal confirmação, essa frase aponta para uma crença no fato de se ter um corpo. Assim, o uso do termo crença denota que o fato de ter um corpo não pode ser uma certeza para o sujeito. Nesse ponto, quanto à questão da distinção entre sujeito e corpo, Lacan vai muito além de Descartes, tendo em vista que para Descartes ter um corpo é uma certeza, enquanto para Lacan é somente uma crença.

\section{O AMOR COMO UM SINTOMA}

Para abordar o amor a partir da diferença sexual, faz-se necessário localizar o amor em sua referência corporal como foi observado.

Ainda trabalhando a diferença entre as disposições de amor tanto no masculino, quanto no feminino, pode-se utilizar a referência de Lacan em $O$ Seminário - $O$ Sinthoma, quando Lacan explicita a impossibilidade da relação entre os sexos e acrescenta

que a não-relação se apresenta como uma falta de equivalência. Em suas palavras: uma mulher é para todo homem um sinthoma. Para o que é do homem para uma mulher, deve-se encontrar um outro nome, já que o sinthoma se caracteriza pela não-equivalência. $\mathrm{O}$ homem é para uma mulher tudo o que lhes agradará, uma aflição pior que um sinthoma, uma devastação mesmo (LACAN, 1976-77, p. 20).

Se o homem faz da mulher seu sinthoma, ele a transforma em seu objeto de gozo ao qual o significante se articula. Já no caso de uma mulher, não existe a possibilidade de que o homem se transforme em seu objeto de gozo e, muito menos, que a isso se associe o significante. Para uma mulher, Lacan aponta, o homem é pior que uma aflição - é uma devastação.

Em aproximação às noções de sinthoma e devastação, acompanhamos Jacques-Alain Miller que propõe sobre esse sujeito uma oposição tópica. Para Miller, o sintoma, do qual deriva a noção de sinthoma, traduz um modo de gozo masculino, "um sofrimento sempre limitado, um sofrimento localizado" (MILLER, 1999, p. 15). Desse modo, segundo ele, os sintomas podem ser classificados e podem ser tratados. Já, a devastação tipicamente feminina é uma dor sem limites e inclassificável. Miller opõe entre os dois modos de gozo a noção de limite e semlimites, finito e infinito. A devastação, se a tomamos em relação à natureza, esten- 
de-se para todos os lados, sem limites. Como afeto, ela é uma manifestação de amor, em alternância de amor e ódio, que não passa pela limitação do significante. Para a relação da mulher com o homem, a devastação se manifesta como um amor sem palavras que revela certa liberdade tomada pela mulher em relação à mediação fálica. Não obstante, nesse amor feminino devastador, a mulher não se reduz a uma vítima pronta para o sacrifício. Sendo a devastação ilimitada, alastrase por todos os cantos. $\mathrm{O}$ homem, na relação devastadora, também é uma vítima dessa doença de amor que o contamina.

A devastação como modo de gozo feminino está diretamente ligada a um outro modo de gozo, também feminino, nomeado como deslumbramento. Esses dois modos de gozo dão ares de serem absolutamente diferentes ou mesmo opostos, uma vez que a devastação que se mostra como uma destruição sem limites e o deslumbramento ou êxtase se apresentam como um gozo que eleva o corpo a uma outra realidade. A devastação se apresenta como um desprazer e o êxtase como um prazer, ambos sem limites. A aparente oposição se desmonta no sem-limites de ambas as formas de gozo. Se, na devastação, o sem-limites se delineia na falta de mediação significante que marca a palavra como uma reivindicação fálica; no êxtase, o sem-limites ultrapassa a reivindicação fálica e atinge diretamente o corpo em forma de arroubamento. Marie-Helène Brousse, no texto Devastação $e$ desejo do analista, propõe que "a devastação é o deslumbramento" (BROUSSE, 2000), ou êxtase. Para a autora,

O deslumbramento pode tomar a forma de uma rejeição visceral de seu próprio corpo, de uma despersonalização ligada a uma desfalicização, de um auto-desaparecimento. [...] é uma forma de perda não simbolizável, a perda pelo sujeito da imagem de seu corpo no desejo do Outro (BROUSSE, 2000).

Na devastação, a ênfase está na reivindicação do significante que falta; já no deslumbramento, o modo de gozo se manifesta enquanto desaparecimento do corpo próprio. Se, de um lado, não há palavras, de outro, não há corpo. Como não há oposição entre uma e outra posição, elas se encontram no mesmo ilimitado da ausência do significante que as mobiliza; por isso, são indizíveis. Segundo Brousse (2000, p. 19), "é freqüentemente nos confins do dispositivo da palavra, no espaço das paixões do ser, que se produz o dilaceramento que abre de novo esta zona de deslumbramento".

Para Lacan, o fato de o sujeito poder ter um corpo é apenas um efeito consistente de sua imaginação, pois se o imaginário não mantém a consistência do corpo, este pode ser perdido. Segundo Lacan, na sessão de 13 de janeiro de 1976, de O Seminário - O Sinthoma, o falante

[...] adora seu corpo. Ele o adora por crer que o tem. $\mathrm{Na}$ realidade ele não o tem. Mas seu corpo é sua única consistência, mental bem entendido. Seu corpo desaparece a todo instante. É muito milagroso que ele subsista durante tanto tempo, o tempo desta consumação que é de fato, do fato de o dizer, inexorável, nisso que nada acontece porque ela não é 
reabsorvente. É um fato constatado mesmo nos animais, o corpo não se evapora, ele é consistente. E é o que ele é, para a mentalidade, antipática, unicamente porque ela, ela acredita, ter um corpo a adorar. É a raiz do imaginário (LACAN, 197677, p. 12).

Desse modo, no seu entender, a única maneira de um sujeito ter um corpo se mostra pela via do imaginário. Como o sujeito só pode ter um corpo a partir do pensamento imaginário, de sua imaginação, na realidade ele não o tem. É pelo fato de possuí-lo apenas mentalmente que o sujeito pode perder seu corpo.

Em O Seminário - O Sinthoma, Lacan esclarece que o sintoma é "um acontecimento de corpo" (LACAN, 1976-77, p. 35) e, que, por seu intermédio, um sujeito pode encontrar outros corpos. Assim, no seu entender, "os indivíduos que Aristóteles toma por corpos podem ser eles mesmos os sintomas de outros corpos" (LACAN, 1976-77, p. 35). Dessa forma, não podemos dizer que o sujeito tem um corpo próprio, pois o que é da ordem do sujeito pode estar se manifestando em um outro corpo distinto. Para ele, "uma mulher, por exemplo, ela é sintoma de um outro corpo" (LACAN, 1976-77, p. 35). Uma mulher pode ser o sintoma de um homem. Pensando assim, o corpo de uma mulher pode ser manifestação do sintoma do sujeito masculino que é o seu parceiro. Dessa maneira, o sujeito vai encontrar seu corpo na mulher que ele escolheu como parceira.

As múltiplas manifestações do amor colocam sempre em relação duas realidades distintas que, necessariamente, não se relacionam. Seja um homem e uma mulher, seja a filosofia e a psicanálise.

\section{REFERÊNCIAS}

BROUSSE, M-H. Ravage et désir de l'analyste. ORNICAR? Digital: revue eletronique multilingue de psychanalyse, Paris, n.145, oct. 2000.

DESCARTES, R. As paixões da alma. São Paulo: Abril Cultural, 1979a.

. Meditações Metafísicas. 2 ed. São Paulo: Abril Cultural, 1979b.

. O discurso do método. 2 ed. São Paulo: Abril Cultural, 1979c.

KOYRÉ, A. Entretiens sur Descartes. Paris: Gallimard, 1962.

LACAN, J. Le Séminaire: Encore. Paris: Seuil, 1975. Livre 20.

. Le Séminaire: Le transfert. Paris: Seuil, 1991. LivreVIII

. L'étourdit. In: . Scilicet. Paris: Seuil, 1973. n. 04.

. Le Sinthome : l'ego de Joyce. Ornicar, Paris, n.8, 1976-77.

. Le Sinthome: paroles imposés. Ornica, Paris, n.8, 1976-77.

. La science et la vérité. In: Écrits. Paris : Seuil, 1966.

MILLER, J. A. Biologia Lacaniana. Opção lacaniana. São Paulo, n. 41, dez.2004. 
1997.

Elementos para uma biologia lacaniana. Belo Horizonte: Autêntica,

MILLER, J. A. Un Repartitoire Sexuel. La cause freudienne: revue de psychanalyse, Paris, n. 40. jan.1999.

MILNER, J-C. L'Oeuvre claire: Lacan, la science, la philosophie. Paris: Seuil, 1995.

REGNAULT, F. Je rougis, je pâlis à sa vue. Maladies d'amour: Revue de Psychanalise de la Cause Freudienne, Paris, n. 40, jan. 1999.

Recebido em: abril/2005 Aceito em: março/2006 